\title{
Comparison of coconut water and a carbohydrate-electrolyte sport drink on measures of hydration and physical performance in exercise-trained men
}

\author{
Douglas S Kalman ${ }^{1}$, Samantha Feldman ${ }^{1}$, Diane R Krieger ${ }^{1}$ and Richard J Bloomer ${ }^{2^{*}}$
}

\begin{abstract}
Background: Sport drinks are ubiquitous within the recreational and competitive fitness and sporting world. Most are manufactured and artificially flavored carbohydrate-electrolyte beverages. Recently, attention has been given to coconut water, a natural alternative to manufactured sport drinks, with initial evidence indicating efficacy with regard to maintaining hydration. We compared coconut water and a carbohydrate-electrolyte sport drink on measures of hydration and physical performance in exercise-trained men.

Methods: Following a 60-minute bout of dehydrating treadmill exercise, 12 exercise-trained men (26.6 \pm 5.7 yrs) received bottled water (BW), pure coconut water (VitaCoco ${ }^{\circledR}: \mathrm{CW}$ ), coconut water from concentrate (CWC), or a carbohydrate-electrolyte sport drink (SD) [a fluid amount based on body mass loss during the dehydrating exercise] on four occasions (separated by at least 5 days) in a random order, single blind (subject and not investigators), cross-over design. Hydration status (body mass, fluid retention, plasma osmolality, urine specific gravity) and performance (treadmill time to exhaustion; assessed after rehydration) were determined during the recovery period. Subjective measures of thirst, bloatedness, refreshed, stomach upset, and tiredness were also determined using a 5-point visual analog scale.
\end{abstract}

Results: Subjects lost approximately $1.7 \mathrm{~kg}$ ( $\sim 2 \%$ of body mass) during the dehydrating exercise and regained this amount in a relatively similar manner following consumption of all conditions. No differences were noted between coconut water (CW or CWC) and SD for any measures of fluid retention $(p>0.05)$. Regarding exercise performance, no significant difference $(p>0.05)$ was noted between BW (11.9 $\pm 5.9 \mathrm{~min}), \mathrm{CW}(12.3 \pm 5.8 \mathrm{~min})$, CWC (11.9 $\pm 6.0 \mathrm{~min})$, and SD (12.8 $\pm 4.9 \mathrm{~min})$. In general, subjects reported feeling more bloated and experienced greater stomach upset with the CW and CWC conditions.

Conclusion: All tested beverages are capable of promoting rehydration and supporting subsequent exercise. Little difference is noted between the four tested conditions with regard to markers of hydration or exercise performance in a sample of young, healthy men. Additional study inclusive of a more demanding dehydration protocol, as well as a time trial test as the measure of exercise performance, may more specifically determine the efficacy of these beverages on enhancing hydration and performance following dehydrating exercise.

Keywords: Hydration, Coconut Water, Sport Drink, Exercise

\footnotetext{
* Correspondence: rbloomer@memphis.edu

${ }^{2}$ The University of Memphis, Cardiorespiratory/Metabolic Laboratory, Department of Health and Sport Sciences, 106 Roane Fieldhouse, Memphis,

TN 38152

Full list of author information is available at the end of the article
} 


\section{Background}

Fluid loss during strenuous, long duration exercise is commonplace and can result in thermal stress, impaired cognition and cardiovascular function, accelerated fatigue, and impaired exercise performance [1,2]. Recommendations for fluid intake before, during, and following exercise are well described [3,4] and are typically followed by most athletes seeking enhanced physical performance. Abiding by such recommendations appears particularly important when exercising in hot and humid environmental conditions, where fluid loss may be high [5].

Although water is often suggested to many general fitness enthusiasts who may exercise for relatively short periods of time ( $<75$ minutes), carbohydrate-electrolyte sport drinks are highly recommended and appear to be the beverage of choice for most serious athletes-aerobic athletes in particular [2]. This is partly fueled by scientific recommendations for the consumption of such beverages $[6,7]$, and partly by the widespread marketing campaigns of large sport nutrition and beverage companies. Regardless, carbohydrate-electrolyte beverages are widely consumed and represent a multi-billion dollar segment of the food and beverage industry [8].

Some individuals prefer natural alternatives to the manufactured sport drinks. For example, many sport drinks contain fructose and/or maltodextrin, artificial flavors and sweeteners, and added electrolytes (e.g., sodium, potassium). With more emphasis recently within the sport nutrition industry on "natural" beverages, some athletes and recreationally active fitness enthusiasts seek alternatives to the manufactured sport drink. While water is indeed a reasonable solution for some, those involved in longer duration exercise bouts often require and demand carbohydrate and electrolytes within their beverage of choice. For these individuals, coconut water may be considered as one viable alternative.

Coconut water is naturally occurring, is very rich in potassium, contains sodium, chloride, and carbohydrate [9], and is viewed as the hydrating beverage of choice in certain parts of the world [10]. Clinically, coconut water may be used as an oral rehydration aid to replace fluid loss from the gastrointestinal tract in patients suffering severe dehydration due to diarrhea $[11,12]$. It has also been used intravenously with success [13]. Although not linked specifically to hydration, coconut water has been reported to have antioxidant properties [14], which may aid in neutralizing reactive oxygen species production resulting from long duration exercise [15].

In relation to sport nutrition, coconut water has been reported to provide hydrating effects similar to those of carbohydrate-electrolyte sport drinks [16-18]. Unfortunately, these studies have focused exclusively on hydration measures as primary outcome variables (following a period of dehydrating exercise and consumption of the assigned beverage), while not emphasizing actual exercise performance during the rehydrating period. Hence, while the rehydrating effects of coconut water may be similar to those of carbohydrate-electrolyte sport drinks, an equally important question for most athletes and coaches is whether or not the hydration status equates to actual physical performance. Considering the above, we investigated the effects of two different forms of coconut water (concentrated and not from concentrate) and a carbohydrate-electrolyte sport drink on measures of hydration status and physical performance in exercise-trained men.

\section{Methods}

\section{Subjects and Screening}

Exercise-trained men were recruited to participate. Eligibility was determined by completion of a health history form (Physical Activity Readiness Questionnaire [PARQ]) and physical examination. Prior to the start of the study, subjects were engaged in a program of regular exercise for a minimum of the past six months, without difficulty in walking or running on a treadmill. All subjects were instructed to maintain their pre-study exercise program throughout the course of the study, with the exception of refraining from exercise during the 24 hours prior to each test day. Subjects were nonsmokers, did not report any history of cardiovascular, metabolic, neurological, or orthopedic disorders that may have impacted their ability to participate in the study, and did not start the use of any new nutritional supplement over the course of the study; however, they were allowed to continue using nutritional supplements they had been using prior to beginning the study (e.g., multivitamins). Prior to participation, each subject was informed of all procedures, potential risks, and benefits associated with the study through both verbal and written form in accordance with the approved procedures of the Aspire Institutional Review Board for Human Subjects Research (La Mesa, CA; approval date of December 23, 2010). Subjects signed an informed consent form prior to being admitted into the study.

At the initial screening visits, subjects' height via stadiometer (Holtain Limited; Britain) and body mass via digital scale (Detecto; Webb City, MO) were measured and recorded. Body mass was obtained with subjects wearing only a gown and their underwear. Body mass measures following exercise were obtained only after subjects were thoroughly towel dried. Heart rate and blood pressure (using subjects' left arm) were recorded following a minimum of five minutes of quiet rest, while subjects were seated in a chair. A 12-lead 
Table 1 Characteristics of 12 exercise-trained men

\begin{tabular}{|c|c|}
\hline Variable & Value \\
\hline Age at Screening (years) & $\begin{array}{c}26.6 \pm 5.7 \\
24.0(21.0-35.0)\end{array}$ \\
\hline \multicolumn{2}{|l|}{ Ethnicity } \\
\hline Hispanic & $12(100 \%)$ \\
\hline Total & $12(100 \%)$ \\
\hline Race & $12(100 \%)$ \\
\hline Caucasian & $12(100 \%)$ \\
\hline Total & $12(100 \%)$ \\
\hline Height (cm) & $\begin{array}{c}175.4 \pm 4.1 \\
175.0(168.6-181.2)\end{array}$ \\
\hline Body Mass at Screening (kg) & $\begin{array}{c}77.2 \pm 6.3 \\
78.4(66-85.8)\end{array}$ \\
\hline Body Mass Index $\left(\mathrm{kg} \cdot \mathrm{m}^{-2}\right)$ & $\begin{array}{c}25.1 \pm 1.8 \\
26.1(21.5-26.9)\end{array}$ \\
\hline Systolic Blood Pressure (mm Hg) & $\begin{array}{c}118.4 \pm 13.2 \\
120.5(97.0-145.0)\end{array}$ \\
\hline Diastolic Blood Pressure (mm Hg) & $\begin{array}{c}73.9 \pm 6.7 \\
74.0(64.0-87.0)\end{array}$ \\
\hline Heart Rate (beats $\cdot$ minute $^{-1}$ ) & $\begin{array}{c}68.8 \pm 14.4 \\
66.5(48.0-99.0)\end{array}$ \\
\hline Glucose $\left(m g \cdot d L^{-1}\right)$ & $\begin{array}{c}92.5 \pm 4.0 \\
91.5(87.0-99.0)\end{array}$ \\
\hline Blood Urea Nitrogen $\left(\mathrm{mg} \cdot \mathrm{dL}^{-1}\right)$ & $\begin{array}{c}15.2 \pm 3.0 \\
16.0(9.0-19.0)\end{array}$ \\
\hline Creatinine $\left(\mathrm{mg} \cdot \mathrm{dL}^{-1}\right)$ & $\begin{array}{c}1.0 \pm 0.2 \\
1.0(0.7-1.2)\end{array}$ \\
\hline Alkaline Phosphatase (Units $\cdot L^{-1}$ ) & $\begin{array}{c}82.0 \pm 41.0 \\
73.0(32.0-177.0)\end{array}$ \\
\hline Aspartate Amino Transaminase (Units $\cdot L^{-1}$ ) & $\begin{array}{c}21.4 \pm 4.4 \\
20.5(16.0-29.0)\end{array}$ \\
\hline Alanine Amino Transferase (Units $\cdot L^{-1}$ ) & $\begin{array}{c}20.8 \pm 5.8 \\
21.0(11.0-30.0)\end{array}$ \\
\hline White Blood Cell count (thousands $\cdot \mu \mathrm{L}^{-1}$ ) & $\begin{array}{c}6.9 \pm 1.7 \\
6.7(4.2-9.8)\end{array}$ \\
\hline Red Blood Cell count (millions $\cdot \mu L^{-1}$ ) & $\begin{array}{c}5.3 \pm 0.4 \\
5.3(4.5-6.1)\end{array}$ \\
\hline Hemoglobin $\left(\mathrm{g} \cdot \mathrm{dL}^{-1}\right)$ & $\begin{array}{c}15.0 \pm 1.0 \\
15.3(13.1-16.0)\end{array}$ \\
\hline Hematocrit (\%) & $\begin{array}{c}47.7 \pm 3.0 \\
47.9(42.8-52.2)\end{array}$ \\
\hline
\end{tabular}

Data are mean \pm SD (top row); median and (range) provided in bottom row

electrocardiogram was obtained and analyzed for normality, to ensure subject suitability for participation. Blood samples were collected from subjects for routine assessment of clinical chemistry parameters (e.g., metabolic panel and complete blood count). Please see Table 1 for subject descriptive characteristics. A familiarization trial of the exercise performance test was also conducted during the initial laboratory visit. A description of this test is provided below.

\section{Test Days}

On each of the four test days, subjects reported to the lab in the morning following an overnight fast (no food or beverages other than water were allowed after midnight). The time of day for testing each subject was matched for all subsequent test days ( \pm 60 minutes). Subjects were instructed not to exercise or to consume alcohol during the 24 hours prior to each test day, but to consume water liberally up to the time they reported to the lab for testing. Adherence to study instructions was confirmed with all subjects on each day of testing. Following all baseline assessments, subjects were provided with a standardized breakfast consisting of a bagel and one tablespoon of cream cheese. They were also provided with up to $470 \mathrm{~mL}$ of water.

\section{Dehydrating Exercise Test}

Sixty minutes following the conclusion of the standardized breakfast, subjects performed the dehydrating exercise test. It should be noted that of the total of 48 test visits (12 subjects $\times 4$ visits), slight deviations in the time from food intake to the start of the dehydrating exercise test were noted for 14 of the tests (i.e., started before or after the set 60 minute time). Specifically, nine tests were conducted within 15 minutes of this time, two tests were conducted within 30 minutes of this time, and three tests were conducted within 45 minutes of this time. We do not believe these deviations significantly influenced the findings; in particular considering that these were equally dispersed among the four conditions.

The dehydrating exercise consisted of two, 30-minute bouts of walking/jogging, interspersed with a 10 minute rest period. Specifically, subjects walked/jogged at 2, 3, 4, 5, 6 and 7 miles per hour on a motorized treadmill, using a grade of $0 \%$. Five minutes of exercise was performed at each speed. Following the initial 30 minutes of exercise, a 10-minute break was allowed, during which time subjects walked around and/or remained seated. Subjects then repeated the above sequence of speeds for an additional 30 minutes of exercise. Hence, a total of 60 minutes of exercise was performed within the 70 minute period. All exercise was performed in a climate controlled room, with an average temperature of $36^{\circ}$ Celsius and an average relative humidity of $48 \%$. This dehydrating exercise protocol has been reported to induce a 2 to $3 \%$ reduction in body weight [19]. During the three hour period from the end of the dehydrating exercise test to the start of the performance exercise test, subjects were required to rest quietly without food or beverage intake (with the exception of the assigned condition). During this time, as well as during the performance exercise test, subjects remained in a thermoneutral environment (i.e., 22 degrees Celsius).

\section{Conditions}

Within minutes following the conclusion of the dehydrating exercise test (after all measurements were 
obtained-see Table 2), subjects received their assigned condition (beverage). The study design involved a random order, single blind (subject and not investigators), cross-over assignment to one of the following four conditions: Supermarket brand bottled water, pure coconut water (VitaCoco ${ }^{\circledR}$; New York, NY), coconut water from concentrate, or a carbohydrate-electrolyte sport drink (5-6\% carbohydrate solution). The amount of each beverage was determined based on the total amount of body mass lost during the dehydrating exercise protocol using the equation: $1300 \mathrm{~mL} \cdot \mathrm{kg}^{-1} \times \mathrm{kg}$ loss = amount of beverage consumed $(\mathrm{mL})$. This provided a weighted volume amount of beverage equal to approximately $125 \%$ of the actual body mass lost. Based on this, the amount of beverage consumed equated to $2159 \pm 249$ $\mathrm{mL}$ for bottled water, $2220 \pm 367 \mathrm{~mL}$ for VitaCoco ${ }^{\circledR}$, $2253 \pm 358 \mathrm{~mL}$ for coconut water from concentrate, and $2184 \pm 358 \mathrm{~mL}$ for the sport drink, with no differences noted between conditions $(p>0.05)$. Subjects were allowed 60 minutes to consume the entire volume of beverage. Each condition was consumed on a different test day, with a minimum of five days separating test visits.

\section{Performance Exercise Test}

Three hours after the completion of the dehydrating exercise test (and two hours after subjects consumed their assigned condition), a test of physical performance was conducted using a treadmill as previously done [20]. Specifically, subjects began walking on a motorized treadmill at a self-selected comfortable speed ( $0 \%$ grade) for five minutes. At the conclusion of the five-minute period, the actual performance test began. The protocol involved an increase in intensity every three minutes.
While the speed of the treadmill remained constant at 4.2 miles per hour throughout the test, the grade increase in the following manner: $\min 1-3,0 \%$; min 4-6, $2.5 \%$; $\min 7-9,5 \%$; $\min 10-12,7.5 \%$; $\min 13-15,10 \%$; min 16-18, 12.5\%; min 19-21, 15\%. Subjects exercised until volitional exhaustion and the total exercise time was recorded. This identical protocol was administered at the screening visit (for familiarization) and on each of the four test day visits. Therefore, we do not believe that there was any significant degree of "learning" involved with this test.

\section{Outcome Measures}

In addition to the measure of total exercise time obtained in the performance test described above, the following variables were used as outcome measures; some of which have been discussed previously [21]. With regard to hydration status, body mass, fluid retention (based on body mass), plasma osmolality, and urine specific gravity were measured. Specifically, for fluid retention based on body mass, it was expected that the administration of test product at the amount prescribed would bring the subject's body mass back to very near its pre-exercise level. The rehydrating efficacy of the test product was indicated by how well this volume of fluid was retained over the two hours following consumption. Therefore, the body mass immediately post beverage consumption (which occurred at 1 hour post dehydrating exercise) was considered the "baseline"; this was subtracted from the body mass values at 2 and 3 hours post dehydrating exercise, and this difference was divided by the mass of beverage that had been consumed, then multiplied by 100 to yield the "percent of rehydrating fluid retained" at 2 and 3 hours. It should be noted that

Table 2 Study timeline and outcome measures

\begin{tabular}{|c|c|c|c|c|c|c|}
\hline $\begin{array}{l}\text { Time } \rightarrow \\
\text { Variable } \downarrow\end{array}$ & $\begin{array}{l}\text { Pre } \\
\text { Dehydrating } \\
\text { Exercise Test }\end{array}$ & $\begin{array}{l}\text { Immediately Post } \\
\text { Dehydrating Exercise } \\
\text { Test }\end{array}$ & $\begin{array}{l}1 \text { Hour Post } \\
\text { Dehydrating } \\
\text { Exercise Test }\end{array}$ & $\begin{array}{l}2 \text { Hours Post } \\
\text { Dehydrating } \\
\text { Exercise Test }\end{array}$ & $\begin{array}{l}3 \text { Hours Post } \\
\text { Dehydrating } \\
\text { Exercise Test } †\end{array}$ & $\begin{array}{l}\text { Immediately Post } \\
\text { Performance Exercise } \\
\text { Test }\end{array}$ \\
\hline $\begin{array}{l}\text { Body } \\
\text { Masst† }\end{array}$ & $x$ & $X^{*}$ & $X^{* *}$ & $x$ & $x$ & \\
\hline $\begin{array}{l}\text { Plasma } \\
\text { Osmolality }\end{array}$ & $x$ & $x$ & & & $x$ & \\
\hline $\begin{array}{l}\text { Urine } \\
\text { Specific } \\
\text { Gravity }\end{array}$ & $x$ & $x$ & & & $x$ & \\
\hline $\begin{array}{l}\text { Subjective } \\
\text { Measures } \\
\text { (VAS) }\end{array}$ & & $x$ & $x$ & $x$ & $x$ & \\
\hline Heart Rate & $x$ & $x$ & & & $x$ & $x$ \\
\hline $\begin{array}{l}\text { Blood } \\
\text { Pressure }\end{array}$ & $x$ & $x$ & & & $x$ & $x$ \\
\hline
\end{tabular}


body mass was accurately determined using an electronic scale with subjects dry and wearing only a gown and underwear. In additional, all fluid volumes delivered to subjects were meticulously measured. Our use of body mass was used as a surrogate efficacy indicator of hydration as done previously [22].

Plasma osmolality and urine specific gravity were determined using standard procedures. Osmolality was determined by freezing point depression. Specific gravity was determined using reagent test strips. Although we did not measure urine osmolality, it has been concluded by Armstrong and colleagues that "urine osmolality and urine specific gravity may be used interchangeably to determine hydration status" [23]. Both plasma osmolality and urine specific gravity have been used previously as indicators of hydration status [24], and were obtained prior to the dehydrating exercise test, immediately following the dehydrating exercise test, and prior to the performance exercise test.

With regard to subjective measures, thirst, bloatedness, refreshed, stomach upset, and tiredness were determined using a 5-point visual analog scale. Answers were scaled from 1 to 5 where 1 was the lowest and 5 was the highest score. These were assessed immediately, 60 minutes, 120 minutes, and 180 minutes following the dehydrating exercise test.

Heart rate and blood pressure were measured at the following times: Prior to the dehydrating exercise test, immediately following the dehydrating exercise test, prior to the performance exercise test, and immediately following the performance exercise test. A schematic of the study timeline for all outcome measures is provided in Table 2.

\section{Physical Activity and Dietary Intake}

Subjects were instructed to maintain their normal physical activity throughout the study period, with the exception of refraining from strenuous physical activity during the 24 hours preceding each test day. They were also given specific instructions regarding abstinence from alcohol consumption during the 24 hours immediately preceding the test days. Dietary intake was to be maintained through the study period, with the exception of reporting to the lab in a fasted state on each of the four test days. No food records were maintained in this study, which may be considered by some to be a limitation of this work.

\section{Statistical Analysis}

The sample size was determined based on convenience and a power analysis was carried out to determine the effect sizes that would provide an $80 \%$ chance of obtaining a significant result of $\mathrm{p} \leq 0.05$, when testing the outcome measures using the paired Student $t$ test. Using a sample of 12 subjects, an $18 \%$ difference in fluid retention between products would be needed to detect statistical significance. All numerical variables were tested for normality by the Anderson-Darling test. Outcome measures as described within the text above for each variable, at each time point, were analyzed by the paired Student t test. All analyses were performed using " $R$ " statistical software (version 2.13.1; $R$ Foundation for Statistical Computing). Statistical significance was set at $\mathrm{p}$ $\leq 0.05$. The data are presented as mean $\pm \mathrm{SD}$.

\section{Results}

\section{Overview and Adverse Effects}

All subjects successfully completed all aspects of this study, with the exception of one subject who was unable to consume the volume of coconut water from concentrate in the allotted time. Therefore, the trial for this subject was not included in the analysis $(\mathrm{n}=11$ for coconut water from concentrate). Very few adverse events were noted and all were characterized as mild (e. g., stomach upset), likely due to the consumption of a high volume of fluid ( $>2$ liters) in a relatively short period of time ( $\leq 60$ minutes).

\section{Performance Data}

Regarding treadmill performance, no significant difference $(\mathrm{p}>0.05)$ was noted in total exercise time between bottled water $(11.9 \pm 5.9$ minutes $)$, VitaCoco ${ }^{\circledR}(12.3 \pm$ 5.8 minutes), coconut water from concentrate (11.9 \pm 6.0 minutes), and sport drink (12.8 \pm 4.9 minutes).

\section{Hydration Data}

In regard to body mass, subjects lost approximately 1.7 $\mathrm{kg}$ during the dehydrating exercise ( $2 \%$ of starting body mass), regained this amount in a similar manner following consumption of all conditions, and slowly lost approximately $1 \mathrm{~kg}$ over the subsequent two hours (Table 3$)$. However, body mass $(\mathrm{p}=0.023)$ was slightly greater with coconut water from concentrate compared only to bottled water (when expressed as change from pre dehydrating exercise at 3 hours post dehydrating exercise). No other differences were noted between conditions for body mass $(\mathrm{p}>0.05)$. In regard to fluid retention (based on body mass), similar findings were observed (as this measure is influenced by body mass), with greater values for coconut water from concentrate compared only to bottled water $(\mathrm{p}=0.041)$ at 3 hours post dehydrating exercise. At 3 hours post dehydrating exercise ( 2 hours after rehydration) values were numerically highest for coconut water from concentrate ( $\sim 52 \%)$, lowest for bottled water $(\sim 35 \%)$, and intermediate for $\mathrm{VitaCoco}{ }^{\circledR}$ and sport drink $(\sim 40 \%)$; although these differences were not statistically significant $(\mathrm{p}>$ 0.05). No other differences were noted between 
Table 3 Body mass of exercise-trained men before and after dehydrating exercise

\begin{tabular}{lcccc}
\hline Time & VitaCoco & Sport Drink & Coconut Water & Bottled Water \\
\hline Pre Dehydrating Exercise & $78.5 \pm 7.4$ & $77.8 \pm 7.1$ & $77.5 \pm 7.6$ & $77.8 \pm 7.6$ \\
& $79.2(65.2-89.0)$ & $78.2(65.2-87.3)$ & $75.6(64.9-88.4)$ & $78.2(64.8-89.3)$ \\
\hline Immediately Post & $76.9 \pm 7.2$ & $76.1 \pm 6.8$ & $75.8 \pm 7.5$ & $76.2 \pm 7.4$ \\
Dehydrating Exercise & $77.4(63.9-87.2)$ & $76.6(63.8-85.3)$ & $73.7(63.3-86.5)$ & $76.5(63.5-87.4)$ \\
\hline 1 hour Post & $78.4 \pm 7.3$ & $77.7 \pm 7.2$ & $77.6 \pm 7.6$ & $77.9 \pm 7.6$ \\
Dehydrating Exercise & $79.0(65.5-88.9)$ & $77.8(65.1-87.6)$ & $75.5(65.0-88.6)$ & $78.1(64.9-90.1)$ \\
\hline 2 hours Post & $78.1 \pm 7.2$ & $77.4 \pm 7.0$ & $77.3 \pm 7.5$ & $77.4 \pm 7.5$ \\
Dehydrating Exercise & $78.3(65.5-88.8)$ & $77.6(65.1-87.0)$ & $75.2(64.8-88)$ & $77.6(64.7-88.9)$ \\
\hline 3 hours Post & $77.6 \pm 6.9$ & $77.0 \pm 6.8$ & $76.9 \pm 7.4$ & $76.9 \pm 7.3$ \\
Dehydrating Exercise* & $78.0(65.5-87.9)$ & $77.2(64.9-86.3)$ & $75.0(64.6-87.6)$ & $76.9(64.5-88.0)$ \\
\hline
\end{tabular}

Data are mean \pm SD (top row); median and (range) provided in bottom row

${ }^{*}$ Coconut water from concentrate greater than bottled water $(p=0.023)$; when expressed as change from Pre Dehydrating Exercise at 3 hours Post Dehydrating Exercise. No other differences noted ( $p>0.05$ ).

conditions for fluid retention ( $p>0.05)$. Data are presented in Table 4. Plasma osmolality displayed similar results as noted for body mass and fluid retention, with greater values for coconut water from concentrate compared only to bottled water $(\mathrm{p}=0.049$; when expressed as change from pre dehydrating exercise at 3 hours post dehydrating exercise). In general, this measure increased after dehydrating exercise, indicating dehydration of the subjects, and returned toward baseline at 3 hours post dehydrating exercise, indicating rehydration of the subjects. No other differences were noted between conditions for plasma osmolality $(\mathrm{p}>0.05)$. Data are presented in Table 5. No differences were noted between conditions for urine specific gravity, with this measure relatively constant and within the normal range over the measurement period $(\mathrm{p}>0.05)$. Data are presented in Table 6.

\section{Subjective Data}

All four conditions quenched thirst with no significant differences between conditions $(p>0.05)$. Subjects reported feeling bloated with all four conditions, as per statistically significant increases at 1 hour post dehydrating exercise. Over the two hour rehydration period, the bloatedness decreased for all four conditions but remained statistically significant at 3 hours post dehydrating exercise for VitaCoco ${ }^{\circledR}(p=0.012)$ and coconut water from concentrate $(p=0.034)$. Subjects generally felt refreshed after rehydration, with a statistically significant increase for bottled water over VitaCoco ${ }^{\circledR}$ at 1 hour post dehydrating exercise $(p=0.036)$. No other differences were noted ( $p>0.05$ ). The two coconutbased products tended to produce more stomach upset than bottled water or sport drink, with significant findings at 3 hours post dehydrating exercise for VitaCoco ${ }^{\circledR}$ and sport drink $(\mathrm{p}=0.034)$, VitaCoco ${ }^{\circledR}$ and bottled water $(p=0.046)$, coconut water from concentrate and sport drink ( $\mathrm{p}=0.020)$ and coconut water from concentrate and bottled water $(\mathrm{p}=0.020)$. Tiredness generally tended to decrease immediately post dehydrating exercise, with no significant differences between conditions ( $\mathrm{p}>0.05)$. All subjective data are presented in Table 7.

\section{Heart Rate and Blood Pressure Data}

No differences were noted between conditions for heart rate, systolic blood pressure, or diastolic blood pressure ( $p>0.05)$. Data for these variables are presented in Table 8 .

Table 4 Fluid retention of exercise-trained men before and after dehydrating exercise

\begin{tabular}{|c|c|c|c|c|}
\hline Time & VitaCoco $^{\circledR}$ & Sport Drink & $\begin{array}{c}\text { Coconut Water } \\
\text { From Concentrate }\end{array}$ & Bottled Water \\
\hline $\begin{array}{l}1 \text { hour Post } \\
\text { Dehydrating Exercise }\end{array}$ & $\begin{array}{c}73.6 \pm 22.1 \\
76.0(30.9-101.5\end{array}$ & $\begin{array}{c}76.4 \pm 21.1 \\
77.9(37.6-101.5)\end{array}$ & $\begin{array}{c}83.5 \pm 9.7 \\
84.0(67.2-101.5)\end{array}$ & $\begin{array}{c}82.1 \pm 22.3 \\
88.0(42.8-115.9)\end{array}$ \\
\hline $\begin{array}{l}2 \text { hours Post } \\
\text { Dehydrating Exercise }\end{array}$ & $\begin{array}{c}59.6 \pm 31.7 \\
71.4(-3.8-99.0)\end{array}$ & $\begin{array}{c}60.6 \pm 19.5 \\
66.8(28.4-90.9)\end{array}$ & $\begin{array}{c}67.6 \pm 13.7 \\
63.0(37.8-85.5)\end{array}$ & $\begin{array}{c}56.9 \pm 26.6 \\
62.1(0.0-95.7)\end{array}$ \\
\hline $\begin{array}{l}3 \text { hours Post } \\
\text { Dehydrating Exercise* }\end{array}$ & $\begin{array}{c}39.0 \pm 37.9 \\
35.7(-42.2-99.0)\end{array}$ & $\begin{array}{c}40.3 \pm 24.9 \\
38.9(-5.7-74.8)\end{array}$ & $\begin{array}{c}51.7 \pm 14.9 \\
46.2(29.4-75.6)\end{array}$ & $\begin{array}{c}34.7 \pm 23.9 \\
32.9(-10.7-65.5)\end{array}$ \\
\hline
\end{tabular}

Data are mean \pm SD (top row); median and (range) provided in bottom row

${ }^{*}$ Coconut water from concentrate greater than bottled water $(p=0.041)$ at 3 hours Post Dehydrating Exercise. No other differences noted ( $\left.p>0.05\right)$. 
Table 5 Plasma osmolality of exercise-trained men before and after dehydrating exercise

\begin{tabular}{lcccc}
\hline Time & VitaCoco $^{\circledR}$ & Sport Drink & $\begin{array}{c}\text { Coconut Water } \\
\text { From Concentrate }\end{array}$ & Bottled Water \\
\hline Pre Dehydrating Exercise & $289.3 \pm 4.5$ & $291.5 \pm 6.0$ & $293.0 \pm 5.6$ & $292.0 \pm 5.0$ \\
& $288.5(282.0-300.0)$ & $290.0(283.0-305.0)$ & $291.0(287.0-305.0)$ & $291.0(282.0-300.0)$ \\
\hline Immediately Post & $297.5 \pm 5.6$ & $297.7 \pm 8.0$ & $297.5 \pm 6.1$ & $297.6 \pm 4.5$ \\
Dehydrating Exercise & $297.5(290.0-309.0)$ & $297.0(289.0-320.0)$ & $296.0(289.0-309.0)$ & $297.5(290.0-305.0)$ \\
\hline 3 hours Post & $291.2 \pm 6.6$ & $289.6 \pm 5.5$ & $291.8 \pm 5.7$ & $290.3 \pm 5.1$ \\
Dehydrating Exercise* & $290.0(285.0-310.0)$ & $288.0(283.0-304.0)$ & $289.0(286.0-306.0)$ & $289.5(284.0-302.0)$ \\
\hline
\end{tabular}

Data are mean \pm SD (top row); median and (range) provided in bottom row

*Coconut water from concentrate greater than bottled water ( $p=0.049$ ); when expressed as change from Pre Dehydrating Exercise at 3 hours Post Dehydrating Exercise. No other differences noted ( $p>0.05$ ).

\section{Discussion}

Findings from the present investigation indicate that all of the tested beverages are capable of promoting rehydration after one hour of dehydrating exercise. With few exceptions at selected time points, findings for all rehydration variables were essentially the same when comparing the carbohydrate-electrolyte sport drink, coconut water (concentrated and not from concentrate), and bottled water. Moreover, no differences were noted in treadmill performance during the rehydration period. These data are specific to a sample of young, exercisetrained, healthy men.

Maintaining hydration status is vital for athletes and can directly impact exercise performance [25]. As such, many studies have been conducted to determine the optimal rehydration strategies. While water intake is likely an adequate rehydration approach for many individuals, others (e.g., athletes involved in vigorous training) may require intake of water-carbohydrate or carbohydrate-electrolyte mixtures [2], in addition to other nutrients [26]. Such an approach has been reported to be superior to water alone and is generally considered the ideal recommendation for individuals engaged in long duration, strenuous bouts of acute exercise $[2,4]$.

Related to the above, the use of coconut water has been considered by many, as this beverage provides a natural source of carbohydrate and electrolytes [9]. Specifically, coconut water has been reported to provide sugar $\left(\sim 1 \mathrm{~g} \cdot \mathrm{dL}^{-1}\right)$, potassium $\left(\sim 51 \mathrm{mEq} \cdot \mathrm{L}^{-1}\right)$, sodium $\left(\sim 33 \mathrm{mEq} \cdot \mathrm{L}^{-1}\right)$, and chloride $\left(\sim 52 \mathrm{mEq} \cdot \mathrm{L}^{-1}\right)[9]$; however, this may vary depending on species of coconut palm. Coconut water has been reported to provide hydrating effects similar to those of carbohydrate-electrolyte sport drinks [16-18].

Saat and colleagues used a cross-over study to assess the effectiveness of fresh young coconut water and a carbohydrate-electrolyte beverage, compared to water on measures of whole body rehydration and blood volume restoration during a two hour rehydration period following a bout of dehydrating exercise [16]. A sample of eight young men participated and consumed the assigned beverage at a volume equal to $120 \%$ of the fluid loss during exercise. No statistically significant differences were noted between conditions for any outcome measure; however, blood volume restoration was noted to be slightly greater for coconut water. This same group reported similar findings in a follow-up study published in 2007 [17], using the same volume of beverages (120\% of fluid loss during exercise). More recently, Idárraga and Aragón-Vargas studied the rehydrating effect of coconut water following exercise [18]. On three different days, six men and five women were dehydrated to approximately $2 \%$ body mass by exercising in a climate-controlled laboratory. On each day and in random order, subjects were rehydrated with fresh coconut water, a sport drink, or plain water using a volume equal to $120 \%$ of body weight lost during exercise. Subjects were then monitored for three hours, with urine collection every 30 minutes. No differences were

Table 6 Urine specific gravity of exercise-trained men before and after dehydrating exercise

\begin{tabular}{lccr}
\hline Time & VitaCoco ${ }^{\circledR}$ & Sport Drink & $\begin{array}{c}\text { Coconut Water } \\
\text { From Concentrate }\end{array}$ \\
\hline Pre Dehydrating Exercise & $1.0204 \pm 0.0087$ & $1.0218 \pm 0.0096$ & $1.0217 \pm 0.0106$ \\
& $1.02(1.01-1.03)$ & $1.03(1.00-1.032)$ & $1.03(1.01-1.03)$ \\
\hline Immediately Post & $1.0158 \pm 0.0102$ & $1.0165 \pm 0.0112$ & $1.0153 \pm 0.0098$ \\
Dehydrating Exercise & $1.02(1.01-1.03)$ & $1.018(1.00-1.03)$ & $1.02(1.00-1.03)$ \\
\hline 3 hours Post & $1.0200 \pm 0.0098$ & $1.0060 \pm 0.0037$ & $1.01-1.03)$ \\
Dehydrating Exercise & $1.03(1.01-1.03)$ & $1.01(1.00-1.02)$ & $1.0139 \pm 0.0066$ \\
\hline
\end{tabular}

Data are mean \pm SD (top row); median and (range) provided in bottom row

No differences noted $(p>0.05)$. 
Table 7 Subjective ratings of exercise-trained men before and after dehydrating exercise

\begin{tabular}{|c|c|c|c|c|}
\hline Time & VitaCoco $^{\circledR}$ & Sport Drink & $\begin{array}{l}\text { Coconut Water } \\
\text { From Concentrate }\end{array}$ & Bottled Water \\
\hline \multicolumn{5}{|l|}{ Thirst } \\
\hline Immediately Post DHE & $4.08 \pm 1.16$ & $4.42 \pm 0.67$ & $4.45 \pm 0.69$ & $4.67 \pm 0.65$ \\
\hline 1 hour Post DHE & $1.17 \pm 0.58$ & $1.33 \pm 0.89$ & $1.36 \pm 0.67$ & $1.08 \pm 0.29$ \\
\hline 2 hours Post DHE & $1.50 \pm 0.52$ & $1.58 \pm 0.67$ & $1.45 \pm 0.52$ & $1.50 \pm 0.67$ \\
\hline 3 hours Post DHE & $1.67 \pm 0.65$ & $1.83 \pm 0.94$ & $1.45 \pm 0.82$ & $1.92 \pm 1.00$ \\
\hline \multicolumn{5}{|l|}{ Bloatedness } \\
\hline Immediately Post DHE & $1.33 \pm 0.49$ & $1.33 \pm 0.65$ & $1.55 \pm 1.04$ & $1.33 \pm 0.49$ \\
\hline 1 hour Post DHE & $3.58 \pm 1.00$ & $3.42 \pm 1.24$ & $4.00 \pm 1.34$ & $3.08 \pm 1.24$ \\
\hline 2 hours Post DHE & $2.75 \pm 0.97$ & $1.67 \pm 0.65$ & $2.82 \pm 1.17$ & $1.50 \pm 0.67$ \\
\hline 3 hours Post DHE & $2.33 \pm 1.23$ & $1.42 \pm 0.67$ & $2.45 \pm 1.21$ & $1.25 \pm 0.62$ \\
\hline \multicolumn{5}{|l|}{ Refreshed } \\
\hline Immediately Post DHE & $1.92 \pm 1.00$ & $2.08 \pm 1.24$ & $2.09 \pm 1.22$ & $1.67 \pm 0.89$ \\
\hline 1 hour Post DHE & $3.25 \pm 1.36$ & $3.83 \pm 1.27$ & $3.82 \pm 1.08$ & $4.17 \pm 1.19$ \\
\hline 2 hours Post DHE & $3.33 \pm 1.23$ & $3.67 \pm 1.23$ & $3.64 \pm 1.50$ & $3.58 \pm 1.16$ \\
\hline 3 hours Post DHE & $3.17 \pm 1.19$ & $3.33 \pm 1.15$ & $3.55 \pm 1.51$ & $3.50 \pm 1.09$ \\
\hline \multicolumn{5}{|l|}{ Stomach Upset } \\
\hline Immediately Post DHE & $1.58 \pm 0.79$ & $1.25 \pm 0.45$ & $1.00 \pm 0.00$ & $1.00 \pm 0.00$ \\
\hline 1 hour Post DHE & $2.75 \pm 1.29$ & $2.00 \pm 1.35$ & $3.18 \pm 1.66$ & $1.67 \pm 0.89$ \\
\hline 2 hours Post DHE & $3.33 \pm 1.23$ & $1.25 \pm 0.62$ & $3.09 \pm 1.51$ & $1.25 \pm 0.45$ \\
\hline 3 hours Post DHE & $2.92 \pm 1.31$ & $1.17 \pm 0.39$ & $2.55 \pm 1.44$ & $1.08 \pm 0.29$ \\
\hline \multicolumn{5}{|l|}{ Tiredness } \\
\hline Immediately Post DHE & $3.58 \pm 1.00$ & $3.92 \pm 0.79$ & $3.82 \pm 0.98$ & $4.08 \pm 0.79$ \\
\hline 1 hour Post DHE & $2.83 \pm 0.83$ & $3.08 \pm 0.90$ & $2.64 \pm 0.92$ & $2.92 \pm 1.00$ \\
\hline 2 hours Post DHE & $2.08 \pm 0.90$ & $2.58 \pm 0.90$ & $2.36 \pm 0.81$ & $2.33 \pm 0.98$ \\
\hline 3 hours Post DHE & $2.08 \pm 0.90$ & $2.50 \pm 1.00$ & $2.18 \pm 0.98$ & $2.33 \pm 0.78$ \\
\hline
\end{tabular}

Data are mean \pm SD

Thirst: No differences between conditions ( $p>0.05$ ).

Bloatedness: 3 hours Post DHE > Immediately Post DHE for VitaCoco ${ }^{\circledR}(p=0.012)$ and coconut water from concentrate $(p=0.034)$

Refreshed: 1 hour Post DHE > Immediately Post DHE for bottled water compared to VitaCoco ${ }^{\mathbb{R}}(\mathrm{p}=0.036)$.

Stomach Upset: Greater stomach upset at 3 hours Post DHE for VitaCoco ${ }^{\circledR}$ compared to sport drink $(p=0.034)$, VitaCoco ${ }^{\circledR}$ compared to bottled water $(p=0.046)$, coconut water from concentrate compared to sport drink $(p=0.020)$ and coconut water from concentrate compared to bottled water $(p=0.020)$.

Tiredness: No differences between conditions ( $p>0.05$ ).

$\mathrm{DHE}=$ Dehydrating Exercise

noted between coconut water and sport drink for urine volume or fluid retention (both were better than plain water).

These above studies focused exclusively on hydration measures, following a period of dehydrating exercise and consumption of the assigned beverage, while not emphasizing exercise performance during the rehydrating period. The present study, using a similar fluid volume as used previously, extends these findings by noting similar exercise performance results for natural coconut water (concentrated and not from concentrate) and a carbohydrate-electrolyte sport drink. For most athletes and coaches, this finding is likely of most importance. Our data indicate that coconut water can provide similar benefits as compared to a typical sport drink in terms of exercise performance (as measured based on treadmill time to exhaustion), in addition to measures of hydration. That being said, one potential concern is subject tolerance to coconut water in such high volumes. Subjects reported feeling somewhat bloated and experienced mild stomach upset with the two forms of coconut water used in the present investigation (Table 7), which is likely due to the high volume of fluid required to be consumed in such a short period of time. As with most beverages, individual tolerance to coconut water should be determined prior to use.

It should be noted that this study explored many endpoints at many time-points, each being compared between four products. Consequently, many hundreds of separate pairwise comparisons were carried out, each generating a $\mathrm{p}$ value, raising the issue of multiplicity and inflated Type-1 error. No multiple-test adjustments (Bonferroni or other) were applied - it would have been unrealistic and unproductive to try to establish a study- 
Table 8 Heart rate and blood pressure of exercise-trained men before and after dehydrating exercise

\begin{tabular}{|c|c|c|c|c|}
\hline Time & VitaCoco $^{\circledR}$ & Sport Drink & $\begin{array}{l}\text { Coconut Water } \\
\text { From Concentrate }\end{array}$ & Bottled Water \\
\hline \multicolumn{5}{|l|}{ Heart Rate } \\
\hline Pre DHE & $63.6 \pm 8.7$ & $63.3 \pm 6.7$ & $64.6 \pm 11.6$ & $62.7 \pm 6.5$ \\
\hline Immediately Post DHE & $102.1 \pm 19.9$ & $101.8 \pm 12.8$ & $103.4 \pm 13.0$ & $102.0 \pm 18.1$ \\
\hline Pre PE & $70.2 \pm 11.2$ & $71.2 \pm 9.8$ & $68.5 \pm 9.1$ & $64.2 \pm 7.6$ \\
\hline Immediately Post PE & $86.8 \pm 15.0$ & $88.0 \pm 17.5$ & $96.1 \pm 35.7$ & $84.6 \pm 15.2$ \\
\hline \multicolumn{5}{|l|}{ Systolic Blood Pressure } \\
\hline Pre DHE & $122.8 \pm 9.6$ & $119.6 \pm 9.5$ & $121.0 \pm 9.4$ & $122.3 \pm 8.4$ \\
\hline Immediately Post DHE & $109.2 \pm 9.6$ & $116.8 \pm 12.1$ & $113.6 \pm 11.7$ & $112.7 \pm 4.3$ \\
\hline Pre PE & $122.1 \pm 9.4$ & $116.7 \pm 8.4$ & $120.9 \pm 9.3$ & $117.6 \pm 8.7$ \\
\hline Immediately Post PE & $120.8 \pm 11.9$ & $121.6 \pm 9.6$ & $117.7 \pm 9.9$ & $115.7 \pm 10.3$ \\
\hline \multicolumn{5}{|l|}{ Diastolic Blood Pressure } \\
\hline Pre DHE & $77.8 \pm 5.2$ & $75.0 \pm 7.5$ & $78.3 \pm 7.3$ & $76.7 \pm 3.9$ \\
\hline Immediately Post DHE & $66.8 \pm 7.1$ & $73.1 \pm 7.0$ & $71.1 \pm 7.3$ & $72.2 \pm 5.9$ \\
\hline Pre PE & $76.3 \pm 4.3$ & $74.1 \pm 5.6$ & $74.8 \pm 5.8$ & $73.5 \pm 5.2$ \\
\hline Immediately Post PE & $77.6 \pm 6.6$ & $76.6 \pm 6.4$ & $74.5 \pm 6.6$ & $74.3 \pm 7.5$ \\
\hline
\end{tabular}

Data are mean \pm SD

No differences noted ( $p>0.05$ ).

$\mathrm{DHE}=$ Dehydrating Exercise

$\mathrm{PE}=$ Performance Exercise

wide 0.05 alpha level, which would have required impossibly small p-values on individual tests. So it should be kept in mind that each individual $\mathrm{p}$ value has a one-intwenty chance of being nominally significant $(\mathrm{p}<0.05)$ purely from random fluctuations. Conclusions of relative efficacy among the different products should not be based simply on isolated p values, but rather on a consideration of the complete set of data for each endpoint. Likewise, observed values were not simply put into a repeated-measures ANOVA to test for overall changes over time - most endpoints displayed very significant changes at certain time points (such as from baseline to immediately post-dehydrating exercise). It was much more appropriate to examination the changes (and differences in mean changes between products) only over certain physiologically-meaningful intervals, and individual t-tests were much more directly interpretable, and therefore more useful, in assessing these specific changes.

\section{Conclusion}

Considering the above, our data indicate that both coconut water (natural, concentrated and not from concentrate) and bottled water provide similar rehydrating effects as compared to a carbohydrate-electrolyte sport drink. Moreover, none of the beverages impacted treadmill exercise performance differently during the rehydration period. Additional study is needed with consideration for the inclusion of a more demanding dehydration protocol, aimed at reducing body mass beyond the $2 \%$ mark obtained in the present investigation may be warranted. Finally, while treadmill time to exhaustion is routinely used in laboratory studies, the use of a time trial test as the measure of exercise performance may be more appropriate. Investigators may consider these suggestions when designing future studies focused on the potential rehydrating ability of coconut water and other beverages.

\section{Acknowledgements}

Funding for this work was provided by VitaCoco ${ }^{\oplus}$ Company (New York, NY).

\section{Author details}

${ }^{1}$ Miami Research Associates, Nutrition/Endocrinology Department, 6141 Sunset Drive, Suite 301, Miami, FL 33143. ${ }^{2}$ The University of Memphis, Cardiorespiratory/Metabolic Laboratory, Department of Health and Sport Sciences, 106 Roane Fieldhouse, Memphis, TN 38152.

\section{Authors' contributions}

DSK, SF, and DRK were responsible for the study design, coordination of the study, and oversight of data collection and analysis. RJB assisted in manuscript preparation. All authors read and approved of the final manuscript.

\section{Competing interests}

Financial support for this work was provided by VitaCoco ${ }^{\circledR}$ Company (New York, NY). The investigators have no direct or indirect interest in VitaCoco ${ }^{*}$. RJB has received research funding or has acted as a consultant to nutraceutical and dietary supplement companies.

Received: 15 December 2011 Accepted: 18 January 2012 Published: 18 January 2012

\section{References}

1. Rodriguez NR, DiMarco NM, Langley S, American Dietetic Association, Dietetians of Canada, American College of Sports Medicine: Position of the American Dietetic Association, Dietitians of Canada, and the American 
College of Sports Medicine: Nutrition and athletic performance. J Am Diet Assoc 2009, 109(3):509-27.

2. von Duvillard SP, Arciero PJ, Tietjen-Smith T, Alford K: Sports drinks, exercise training, and competition. Curr Sports Med Rep 2008, 7(4):202-8.

3. American College of Sports Medicine, Sawka MN, Burke LM, Eichner ER, Maughan RJ, Montain SJ, Stachenfeld NS: American College of Sports Medicine position stand. Exercise and fluid replacement. Med Sci Sports Exerc 2007, 39(2):377-90.

4. Von Duvillard SP, Braun WA, Markofski M, Beneke R, Leithäuser R: Fluids and hydration in prolonged endurance performance. Nutrition 2004, 20(7-8):651-6.

5. Convertino VA, Armstrong LE, Coyle EF, Mack GW, Sawka MN, Senay LC Jr, Sherman WM: American College of Sports Medicine position stand. Exercise and fluid replacement. Med Sci Sports Exerc 1996, 28(1):i-vii.

6. Rehrer NJ: Fluid and electrolyte balance in ultra-endurance sport. Sports Med 2001, 31(10):701-15.

7. Kreider RB, Wilborn CD, Taylor L, Campbell B, Almada AL, Collins R, Cooke M, Earnest CP, Greenwood M, Kalman DS, Kerksick CM, Kleiner SM, Leutholtz B, Lopez H, Lowery LM, Mendel R, Smith A, Spano M, Wildman R, Willoughby DS, Ziegenfuss TN, Antonio J: ISSN exercise \& sport nutrition review: research \& recommendations. J Int Soc Sports Nutr 2010, 7:7.

8. , http://researchwikis.com/Sports_Drink_Market: Accessed 10/18/11.

9. Chavalittamrong B, Pidatcha P, Thavisri U: Electrolytes, sugar, calories, osmolarity and $\mathrm{pH}$ of beverages and coconut water. Southeast Asian $J$ Trop Med Public Health 1982, 13(3):427-31.

10. Kuberski T, Roberts A, Linehan B, Bryden RN, Teburae M: Coconut water as a rehydration fluid. N Z Med J 1979, 90(641):98-100.

11. Chavalittamrong B, Pidatcha P, Thavisri U: Electrolytes, sugar, calories, osmolarity and $\mathrm{pH}$ of beverages and coconut water. Southeast Asian $J$ Trop Med Public Health 1982, 13(3):427-31.

12. Adams W, Bratt DE: Young coconut water for home rehydration in children with mild gastroenteritis. Trop Geogr Med 1992, 44(1-2):149-53.

13. Campbell-Falck D, Thomas T, Falck TM, Tutuo N, Clem K: The intravenous use of coconut water. Am J Emerg Med 2000, 18(1):108-11.

14. Mantena SK, Jagadish, Badduri SR, Siripurapu KB, Unnikrishnan MK: In vitro evaluation of antioxidant properties of Cocos nucifera Linn. water. Nahrung 2003, 47(2):126-31.

15. Fisher-Wellman $\mathrm{K}$, Bloomer RJ: Acute exercise and oxidative stress: a 30 year history. Dyn Med 2009, 8:1.

16. Saat $M$, Singh $R$, Sirisinghe $R G$, Nawawi M: Rehydration after exercise with fresh young coconut water, carbohydrate-electrolyte beverage and plain water. J Physiol Anthropol Appl Human Sci 2002, 21(2):93-104.

17. Ismail I, Singh R, Sirisinghe RG: Rehydration with sodium-enriched coconut water after exercise-induced dehydration. Southeast Asian J Trop Med Public Health 2007, 38(4):769-85.

18. Idárraga AP, Aragón-Vargas LF: Post-exercise rehydration with coconut water [abstract]. Med Sci Sports Exerc 2010, 42(5):575.

19. Moran DS, Heled Margaliot M, Shani Y, Laor A, Margaliot S, Bickes E, Shapiro Y: Hydration status measurement by radio frequency absorptiometry in young athletes - a new method and preliminary results. Physiol Meas 2004, 25:51-59.

20. Antonio J, Sanders MS, Ehler LA, Uelmen J, Raether JB, Stout JR: Effects of exercise training and amino acid supplementation on body composition and physical performance in untrained women. Nutrition 2000, 16:1043-1046.

21. Cheuvront SN, Ely BR, Kenefick RW, Sawka MN: Biological variation and diagnostic accuracy of dehydration assessment markers. Am J Clin Nutr 2010, 92(3):565-73

22. Wong SH, Chen Y: Effect of a carbohydrate-electrolyte beverage, lemon tea, or water on rehydration during short-term recovery from exercise. Int J Sport Nutr Exerc Metab 2011, 21(4):300-10.

23. Armstrong LE, Maresh CM, Castellani JW, Bergeron MF, Kenefick RW, LaGasse KE, Riebe D: Urinary indices of hydration status. Int I Sport Nutr 1994, 4(3):265-79.

24. Popowski LA, Oppliger RA, Patrick Lambert G, Johnson RF, Kim Johnson A, Gisolf CV: Blood and urinary measures of hydration status during progressive acute dehydration. Med Sci Sports Exerc 2001, 33(5):747-53.

25. Lopez RM, Casa DJ, Jensen KA, Demartini JK, Pagnotta KD, Ruiz RC, Roti MW, Stearns RL, Armstrong LE, Maresh CM: Examining the influence of hydration status on physiological responses and running speed during trail running in the heat with controlled exercise intensity. $J$ Strength Cond Res 2011, 25(11):2944-54.

26. Spaccarotella KJ, Andzel WD: Building a beverage for recovery from endurance activity: a review. J Strength Cond Res 2011, 25(11):3198-204.

doi:10.1186/1550-2783-9-1

Cite this article as: Kalman et al: Comparison of coconut water and a carbohydrate-electrolyte sport drink on measures of hydration and physical performance in exercise-trained men. Journal of the International Society of Sports Nutrition 2012 9:1.

\section{Submit your next manuscript to BioMed Central and take full advantage of:}

- Convenient online submission

- Thorough peer review

- No space constraints or color figure charges

- Immediate publication on acceptance

- Inclusion in PubMed, CAS, Scopus and Google Scholar

- Research which is freely available for redistribution

Submit your manuscript at www.biomedcentral.com/submit
Ciomed Central 